\title{
The burden and characteristics of tuberculosis/ human immunodeficiency virus (TB/HIV) in South Korea: a study from a population database and a survey
}

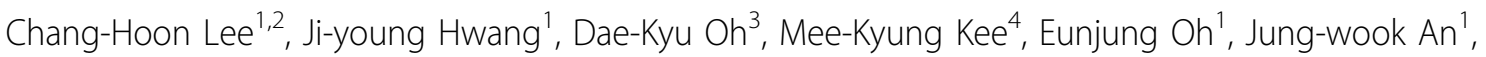
Jinhyun Kim ${ }^{5}$, Heonsook Do ${ }^{1}$, Hee-Jin Kim ${ }^{6}$, Sung Soon Kim ${ }^{4}$, Hwahyun Kim¹, Jeong-Gu Nam ${ }^{1 *}$

\begin{abstract}
Background: Although, in South Korea, human immunodeficiency virus/acquired immunodeficiency syndrome (HIV/AIDS) keeps increasing and tuberculosis(TB) burden is still significant, there have been few reports on TB/HIV cases. In this study, we investigated the burden and characteristics of TB/HIV patients in South Korea, an area with intermediate burden of TB and a low prevalent area with HIV/AIDS.

Methods: We identified patients with TB and cases with HIV between January 12001 and December 31 2005, from nationwide reporting system (TBnet and HIV/AIDS registry) through an electronic record linkage method. A questionnaire survey was also conducted and determined the rate of diagnosis of HIV among TB cases in public health units in 2005.

Results: The number of cases with both HIV and TB was 137 (0.07\% among 197,562 TB cases) and the newly detected TB/HIV cases per 100,000 population was increasing annually: 2001, 0.025; 2002, 0.031; 2003, 0.025; 2004, $0.071 ; 2005,0.095$. Males between 20 and 59 years of age accounted for $87.6 \%$ of TB/HIV patients. Compared with patients with TB alone, those with TB/HIV had a higher percentage of extrapulmonary TB (8.0\% vs 19.0\%; $p<$ 0.0001). The standardized prevalence ratio (SPR) of HIV among patients with TB was 18.46 (95\% Cl, 15.50-21.83). SPR of HIV among male TB patients aged 20-59 and extrapulmonary TB cases was 39.64 (95\% Cl, 32.87-47.40) and 43.21 (95\% Cl, 28.22-63.31) respectively. Through a questionnaire survey of public health units, six patients (0.08\%) were confirmed as having HIV among 7,871 TB patients in public health centers in 2005, which is similar to the result from the study through nationwide reporting systems.
\end{abstract}

Conclusions: The prevalence rate of TB/HIV patients is still low but increasing in South Korea. Physicians should consider performing HIV tests among TB patients, especially in higher-risk groups, such as young males with extrapulmonary TB in South Korea.

\section{Background}

Tuberculosis (TB) and human immunodeficiency virus/ acquired immunodeficiency syndrome (HIV/AIDS) are mankind's major infectious diseases [1,2]. Comorbidity with HIV and TB has been highlighted recently. It is well known that TB and HIV are closely associated. HIV infection contributes to the progression from a recently

\footnotetext{
* Correspondence: jeonggu@nih.go.kr

1 Division of HIV and TB Control, Korea Centers for Disease Control and Prevention, 194 Tongillo, Eunpyung-gu, Seoul, 122-701, Republic of Korea
}

acquired [3] or latent [4] TB infection to the active form of the disease. HIV infection also increases the risk of recurrence of TB [5]. In addition, the relationship between $\mathrm{HIV}$ and drug-resistant TB, including extensively drug resistant (XDR) TB, is cause for concern [6-8]. Conversely, it has been reported that TB may also promote infection [9] with HIV and progression to AIDS [10,11].

According to the World Health Organization, the number of TB cases among HIV-infected people was 0.7 million in 2006, [1] which is significant because HIV is

\section{() Biomed Central}


thought to contribute to TB epidemics, especially in sub-Saharan Africa [12]. It was also reported that treatment of latent TB infection could also prevent TB development in TB/HIV cases [13]. In addition, early detection and intervention for HIV among TB cases are also emphasized [14,15]. The World Health Organization stressed that HIV prevention should be a priority for strategies aimed at controlling TB [16] and that all TB patients should be offered HIV counseling and testing $[1,17]$. However, there could be controversies, because screening tests for HIV have a high rate of false-positive results in countries with low prevalence rate with HIV/AIDS [18]. In addition, how many TB patients underwent HIV testing and how many HIV/ AIDS cases were detected among them in individual countries including South Korea has not been fully investigated [19].

It was reported that HIV/AIDS cases have increased in South Korea since the first case was identified in 1985, in spite of the low prevalence rate under $0.01 \%[20,21]$. Although results from seven nationwide prevalence surveys at five-yearly intervals from 1965 to 1995 revealed a significant decrease in the prevalence of TB [22], South Korea is still regarded as a country with intermediate TB burden; however, studies on the burden and characteristics of TB/HIV cases in South Korea has been rarely reported [1]. The purposes of this study were to document the burden and characteristics of TB/ HIV patients in Korea, which is an area with low HIV/ AIDS prevalence [2] and a country with an intermediate TB burden [1], and to evaluate the contribution of HIV testing among TB patients, by using linkage of national registries, and a survey of public health centers $(\mathrm{PHC})$.

\section{Methods}

\section{Data sources}

The population database for this study consists of three components: Korea TB Surveillance System (KTBS) data, the national registry data of patients with HIV/ AIDS (the HIV/AIDS national registry), and data from Korea National Statistical Office (KNSO). In South Korea, the TB prevention law requires doctors to notify regional public health centers of all cases of TB (In the study, TB refers to 'active TB disease'). Additionally, patients suspicious for having HIV infection (for example, cases with positive anti-HIV antibody testing) undergo confirmatory diagnostic testing using the Western blot method at government institutes and all people diagnosed with HIV/AIDS are registered for monitoring. We used the KTBS and the HIV/AIDS national registry to identify people who were diagnosed with HIV/AIDS and TB between 1 January 2001 and 31 December 2005.
Comorbidity with HIV/AIDS and TB was verified by identifying patients who had been registered both in KTBS and HIV/AIDS national registry using an electronic record linkage method with Standard Query Language (SQL) procedure with SAS version 9.1 (SAS Institute, NC, USA). The year of comorbidity was determined to be the year when the later infection between TB and HIV/AIDS was diagnosed. Demographic data for 2003 were obtained from the KNSO. [23] and were used to characterize the general population at the midpoint between 2001 and 2005. A questionnaire survey was conducted among managers of PHC, which are infrastructures of Korean public health care system, to determine the number of HIV screening tests conducted among TB patients and the rate of diagnosis of HIV in 2005. This study was not submit to an ethics institutional review board as the data we used for this study is existing data including a questionnaire survey that participants cannot be identified, and the dataset is already reviewed by some authorities of Korea Center for Disease Control and Prevention (KCDC) and Korean Institute of Tuberculosis (KIT).

\section{Statistical analyses}

We characterized demographic data according to age/ age group $(0-9,10-19,20-29,30-39,40-49,50-59, \geq 60$ years of age), sex, date of HIV diagnosis, date of initial anti-TB treatment, CD4+ lymphocyte cell count (data was expressed as median with interquartile range (IQL) upon diagnosis of HIV, and type of TB from the data of population database.

To compare the prevalence rates of HIV infection among TB patients and HIV/AIDS infection among the general Korean population, standardized prevalence ratios (SPRs) $[24,25]$ that were adjusted by sex and age were calculated as:

SPR (standardized prevalence ratio) $=\Sigma($ the observed prevalent number $) /$ $\Sigma$ (the expected prevalent number)

The expected number of people with HIV was extrapolated from the prevalence rate of HIV among the survivors of the general population at $30^{\text {th }}$ June, 2003 (the midpoint of the study), which was based on the register of HIV/AIDS and the KNSO. For example, 'SPR of HIV is 5.0 at male TB group' means that the number of observed HIV cases is 5.0 times more than the expected number of HIV cases calculated from the prevalence rate in the general population of men.

The statistical analyses were carried out using the SQL procedures in SAS version 9.1, STATA version 10.1 (StataCorp, Tex, USA) and Microsoft Excel and Powerpoint program (Microsoft, WA, USA) 


\section{Results}

The total number of patients with HIV/AIDS between 1st January, 2001 and 31th December, 2005 was 2,548. Of these, $92.4 \%$ were male. The median age was 37 years (range, 4-80 years). The peak age group was 30-39 years of age (34.3\% of all patients). The annual number of newly detected HIV/AIDS cases per 100,000 people increased with time: 2001, 0.69; 2002, 0.84; 2003, 1.11; $2004,1.27 ; 2005,1.41$. The average increasing rate of cases with HIV was $19.6 \%$ per year (Figure 1). CD4+ lymphocyte cell counts were available for 1,466 patients (57.5\% of all confirmed HIV/AIDS patients). The median CD4+ lymphocyte cell count was 315.0 cells $/ \mathrm{mm}^{3}$ (IRQ, 186.0-464.0).

The total number of patients with TB from 1st January, 2001 to 31th December, 2005 was 197,562. Of these, $62.9 \%$ were male. The median age was 44 years (range, $0-97$ years). Of those less than 60 years of age, the peak age group was $20-29$ years old $(20.1 \%$ of all patients with TB). Most patients had pulmonary TB (92\%, including patients with positive sputum smears [36.4\%]) and $8 \%$ had extrapulmonary TB. The most common type of extrapulmonary TB was TB pleurisy (3.4\% of all patients with TB). (Table 1 )

There were $137 \mathrm{~TB} / \mathrm{HIV}$ patients between 2001 and 2005 , and $96.4 \%$ of these were male. The median age was 39 years (range, 19-79 years). The peak age group was $30-39$ years (37.2\% of all patients), and males aged 20-59 accounted for $87.6 \%$ of the total TB/HIV cases. Annual newly detected TB/HIV cases per 100,000 population increased with time ( $\mathrm{p}<0.001)$ : 2001, 0.025; 2002, 0.031; 2003, 0.025; 2004, 0.071; 2005, 0.095. (Figure 1). Among the patients with TB, $0.07 \%$ had HIV and $5.4 \%$ of the HIV/AIDS patients contracted TB. The number of HIV/AIDS patients who were subsequently diagnosed with TB was greater than the number of patients with TB who subsequently were diagnosed with HIV. The median time interval before HIV patients were registered with TB was 199 days (range, 3-1,455 days); the median time interval before TB patients were diagnosed with HIV was 20 days (range, 1-1,140 days). For patients with comorbidity, the median CD4+ lymphocyte cell count upon diagnosis of HIV was 301.0 cells $/ \mathrm{mm}^{3}$. There was no significant difference in the CD4+ lymphocyte cell count at diagnosis of HIV between patients with HIV alone and patients coinfected with TB and HIV ( $\mathrm{p}=0.587$ by Mann-Whitney U test). There was no significant difference in the CD4 count at diagnosis of HIV between TB patients who subsequently contracted HIV and HIV patients who subsequently contracted TB (median CD4+ lymphocyte cell count, 316.5 cells $/ \mathrm{mm}^{3}$ vs. 268.0 cells $/ \mathrm{mm}^{3} ; \mathrm{p}=0.706$ by Mann-Whitney U test). Compared with patients with TB alone, those with comorbidity had a higher percentage of extrapulmonary TB (OR, 2.69; 95\% CI, 1.75-4.12; $\mathrm{p}<0.0001)$ and similar percentage of sputum smear positivity among pulmonary TB (OR, 0.93; 95\% CI, 0.631.37; $\mathrm{p}=0.715)$. The most common type of extrapulmonary TB in comorbid patients was TB lymphadenitis (7.3\% of all coinfection cases) (Table 1$)$.

The SPR of HIV among overall TB patients was 18.46 (95\% CI, 15.50-21.83). SPR of HIV among male aged 20-59 was 39.64 (95\% CI, 32.87-47.40), while SPR of HIV among male aged $\leq 19$ or $\geq 60$ and among female was 7.33 (95\% CI, 3.78-12.81) and 7.87 (95\% CI, 2.5418.37), respectively. SPR of HIV among cases with extrapulmonary TB was 43.21 (95\% CI, 28.22-63.31), while SPR of HIV among cases with pulmonary TB and
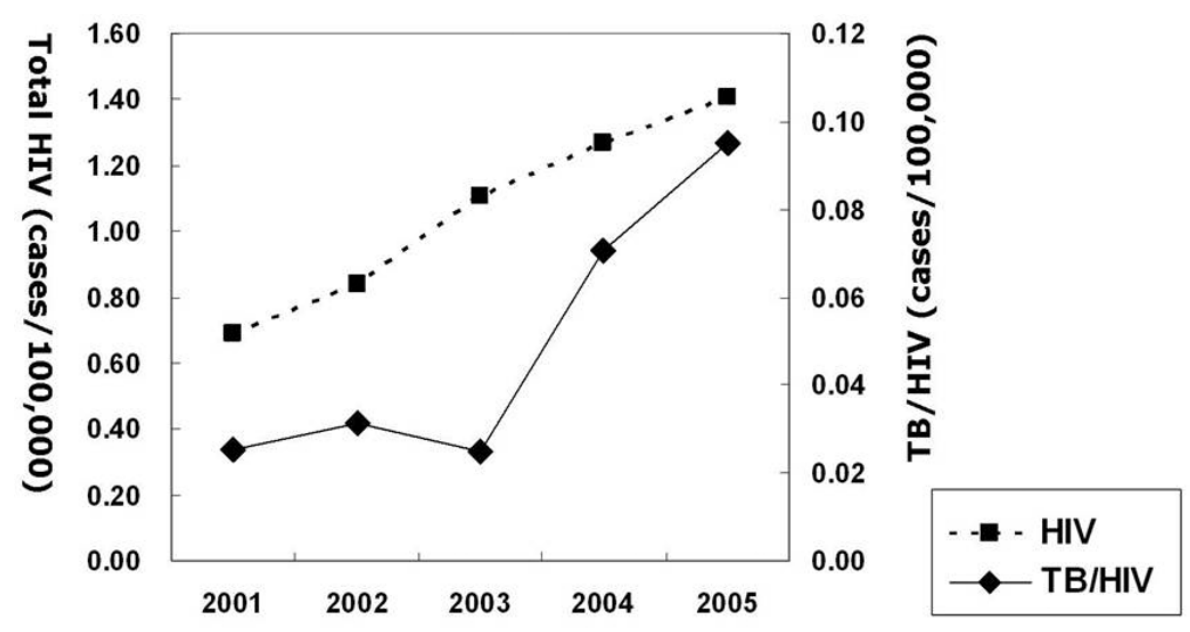

Figure 1 The trends of newly detected HIV infection cases and TB/HIV cases in South Korea (2001-2005) 
Table 1 Characteristics of patients with HIV, patients with TB, and patients with coinfection of TB and HIV in Korea (2001-2005).

\begin{tabular}{|c|c|c|c|c|c|c|}
\hline & \multicolumn{2}{|c|}{$\mathrm{HIV}(\mathrm{N}=2,548)$} & \multicolumn{2}{|c|}{ TB $(\mathrm{N}=197,562)$} & \multicolumn{2}{|c|}{ HIV \& TB $(N=137)$} \\
\hline Sex, male : female & \multicolumn{2}{|c|}{ 2,355(92.4\%):193(7.6\%) } & \multicolumn{2}{|c|}{$124,183(62.9 \%): 73,379(37.1 \%)$} & \multicolumn{2}{|c|}{ 132(96.4\%):5(3.6\%) } \\
\hline Age, median (range) & \multicolumn{2}{|c|}{$37.0(4-80)$} & \multicolumn{2}{|c|}{$44(0-97)$} & \multicolumn{2}{|c|}{$39.5(19.9-79.1)$} \\
\hline $0-9$ & \multicolumn{2}{|c|}{$2(0.1 \%)$} & \multicolumn{2}{|c|}{$1,000(0.5 \%)$} & \multicolumn{2}{|c|}{$0(0 \%)$} \\
\hline $10-19$ & \multicolumn{2}{|c|}{$60(2.4 \%)$} & \multicolumn{2}{|c|}{$12,575(6.4 \%)$} & \multicolumn{2}{|c|}{$1(0.7 \%)$} \\
\hline $20-29$ & \multicolumn{2}{|c|}{$576(22.6 \%)$} & \multicolumn{2}{|c|}{$39.638(20.1 \%)$} & \multicolumn{2}{|c|}{19 (13.9\%) } \\
\hline $30-39$ & \multicolumn{2}{|c|}{$873(34.3 \%)$} & \multicolumn{2}{|c|}{$32,231(16.3 \%)$} & \multicolumn{2}{|c|}{$51(37.2 \%)$} \\
\hline $40-49$ & \multicolumn{2}{|c|}{$583(22.9 \%)$} & \multicolumn{2}{|c|}{$30,515(15.4 \%)$} & \multicolumn{2}{|c|}{$41(29.9 \%)$} \\
\hline $50-59$ & \multicolumn{2}{|c|}{$318(12.5 \%)$} & \multicolumn{2}{|c|}{$23,206(11.7 \%)$} & \multicolumn{2}{|c|}{14 (10.2\%) } \\
\hline $60-$ & \multicolumn{2}{|c|}{$136(5.3 \%)$} & \multicolumn{2}{|c|}{$58,397(29.6 \%)$} & \multicolumn{2}{|c|}{$11(8.0 \%)$} \\
\hline Year & Cases & $\begin{array}{l}\text { Incidence } \\
\left(\text { cases } / 10^{5}\right)\end{array}$ & Cases & $\begin{array}{l}\text { Incidence } \\
(\text { cases/10 })\end{array}$ & Cases & $\begin{array}{l}\text { Incidence } \\
(\text { cases/10 })\end{array}$ \\
\hline 2001 & 327 & 0.69 & 42,737 & 90.3 & 17 & 0.036 \\
\hline 2002 & 398 & 0.84 & 38,801 & 81.4 & 20 & 0.042 \\
\hline 2003 & 534 & 1.11 & 36,227 & 75.6 & 21 & 0.044 \\
\hline 2004 & 610 & 1.27 & 36,041 & 74.8 & 40 & 0.083 \\
\hline 2005 & 680 & 1.41 & 43,781 & 90.7 & 39 & 0.081 \\
\hline CD4 count at diagnosis, median(IQR) $\left(/ \mathrm{mm}^{3}\right)$ & \multicolumn{4}{|c|}{$315.0(186.0-464.0)$} & \multicolumn{2}{|c|}{$301.0(171.5-460.0)$} \\
\hline TB type (\% among patients with TB) & & & & & & \\
\hline Pulmonary & & & 183,640 & & $111(\varepsilon$ & \\
\hline Smear positive & & & 72,599 & & $42(30$ & \\
\hline Extrapulmonary & & & 16,021 & & $26(19$ & \\
\hline Pleurisy & & & $6,852(3$ & & $3(2.2$ & \\
\hline Lymphnode & & & $3,675(1$ & & $10(7$. & \\
\hline Gastrointestinal & & & $1,797(C$ & & $5(3.6$ & \\
\hline Nervous & & & $657(0.3$ & & $3(2.2$ & \\
\hline Skin & & & $272(0.1$ & & $1(0.7$ & \\
\hline Other organs & & & 2,169 & & $1(0.7$ & \\
\hline Disseminated & & & $599(0.3$ & & $3(2.2$ & \\
\hline
\end{tabular}

among semar-positive TB was also 16.09 (95\% CI, 13.2419.38 ) and 15.40 (95\% CI, 11.10-20.82), respectively. (Table 2)

In 2005, HIV screening tests were performed on 7,871 $(60.4 \%)$ of the 13,028 TB patients $(27.7 \%$ of total notified cases) registered with PHC in South Korea. Of these, six patients $(0.08 \%)$, five of whom were male, were confirmed as having HIV.

\section{Discussion}

Our study showed that the number of TB/HIV patients was increasing but the percentage of HIV-infected TB patients was low $(0.07 \%)$ in Korea. The results of questionnaire surveys conducted at PHC were similar $(0.08 \%$ of TB patients was infected with HIV).

The annual number of HIV patients increased by $15.8 \%$ per year between 2001 and 2005. Although the prevalence rate of patients with $\mathrm{TB}$ has decreased in Korea during the last four decades, [22] the number of
TB patients notified was constant or has even increased during the five years of our study period [26]. As the prevalence rate of HIV/AIDS increases, the number of TB patients may also increase because the peak age for HIV and that of TB overlap considerably. For example, in our study, $51.8 \%$ of patients with $\mathrm{TB}, 79.8 \%$ of people living with HIV/AIDS, and $81.0 \%$ of TB/HIV patients were between 20 and 49 years of age. In regions with intermediate-to-high burden $\mathrm{TB}$, it is a common finding that the incidence rate of $\mathrm{TB}$ is high in young age groups $[27,28]$. Although there are other key important issues resulting in $\mathrm{TB} / \mathrm{HIV}$ comorbidity including overlapping risk factors for the transmission of the two diseases such as intravenous drug use [29], which is rarely attributable to transmission of both diseases in South Korea, given that (1) TB is prevalent in young age groups which is probably due to recent infection in regions with intermediate TB burden, (2) HIV/AIDS infection, in which the immune system destruction is 
Table 2 SPR of HIV among overall cases with TB.

\begin{tabular}{|c|c|c|c|c|c|c|}
\hline \multirow[t]{2}{*}{ Subgroup } & \multirow[t]{2}{*}{ No. of TB cases } & \multicolumn{2}{|c|}{ No. of HIV cases } & \multirow[t]{2}{*}{ PR } & \multicolumn{2}{|c|}{$95 \% \mathrm{Cl}$} \\
\hline & & Observed* & Expected & & Lower & Upper \\
\hline \multicolumn{7}{|l|}{ By sex } \\
\hline Male & 124,183 & 132 & 8.21 & 16.09 & 13.46 & 19.08 \\
\hline Female & 73,379 & 5 & 0.65 & 7.87 & 2.54 & 18.37 \\
\hline \multicolumn{7}{|l|}{ By age } \\
\hline $0-9$ & 1,000 & 0 & 0.00 & 0.00 & NA & $7,800.11$ \\
\hline $10-19$ & 12,575 & 1 & 0.03 & 34.87 & NA & 193.99 \\
\hline $20-29$ & 39,638 & 19 & 1.48 & 12.84 & 7.73 & 20.05 \\
\hline $30-39$ & 32,231 & 51 & 2.44 & 20.92 & 15.57 & 27.50 \\
\hline $40-49$ & 30,515 & 41 & 1.98 & 20.75 & 14.89 & 28.16 \\
\hline $50-59$ & 23,206 & 14 & 1.11 & 12.58 & 6.87 & 21.12 \\
\hline $60-$ & 58,397 & 11 & 1.02 & 10.79 & 5.38 & 19.30 \\
\hline Male aged 20-59 & 80,599 & 120 & 3.03 & 39.64 & 32.87 & 47.40 \\
\hline Male aged $<19$ or $\geq 60$ & 43,584 & 12 & 1.64 & 7.33 & 3.78 & 12.81 \\
\hline Pulmonary TB & 183,640 & 111 & 6.90 & 16.09 & 13.24 & 19.38 \\
\hline Smear-positive TB & 72,599 & 42 & 2.73 & 15.40 & 11.10 & 20.82 \\
\hline Extrapulmonary TB & 16,021 & 26 & 0.60 & 43.21 & 28.22 & 63.31 \\
\hline Overall & 197,562 & 85 & 7.42 & 18.46 & 15.50 & 21.83 \\
\hline
\end{tabular}

well-known risk factor of TB development [3,4], is also concentrated in similar age groups and would be an obstacle in TB control in young age, and (3) if TB in young ages were not controlled properly, the future burden of TB would still be substantial because of reactivation in older ages from the latent TB infection, overlapping age in both diseases might be a potential threat of TB control in South Korea.

The percentage of HIV infection among TB patients $(0.07 \%)$ is significantly higher, especially among some subgroups, than that among general population in South Korea $(0.06 \%)$. The SPRs of HIV infection among patients with TB (18.46) were relatively high, which indicated that the risks of having HIV among TB patients were more than 18 times greater than that of the general population. This was comparable to the results of previous studies [27,30,31]. The proportion of HIV infection $(0.07 \%)$ among TB patients notified in South Korea between 2001-2005, and the proportion of HIV infection $(0.08 \%)$ diagnosed by screening test among TB patients of PHC in 2005 in our study are also much greater than the prevalence rate of HIV among general Korean population in 2005, which was 6.4 cases per 100,000 population $(0.006 \%)$. Therefore, HIV screening of TB patients may be worthwhile in settings such as ours. In addition, we wondered if the low prevalence rate of comorbidity with HIV could indicate TB patients with a high risk of HIV infection should be selected for HIV testing. Knowledge of the epidemiological characteristics of patients with comorbidity, which is affected by the prevalence rate of TB and HIV and the route of transmission of HIV infection, would be helpful $[27,29,32,33]$. In our study, most patients with TB/HIV were young males, who were mainly caused by this group having a higher sexual activity and being at the peak age for HIV. Most patients acquired HIV by sexual contact (more than $98 \%$ of all patients [20]), including a relatively high proportion of homosexual contact with HIV-infected persons (reported as $40 \%$ [20], but estimated as more than 50\%; data not shown) in South Korea. Patients with comorbidity tended to have a greater proportion of extrapulmonary TB than did patients with TB alone. Among patients with pulmonary TB, those infected with HIV had a lower rate of positive sputum smears than did those with $\mathrm{TB}$ alone, although statistical significance could not be demonstrated in our cohort. This result agrees with that of a previous report, which showed that, in patients with HIV/AIDS, especially in the late stage of HIV infection, TB is often atypical in presentation, frequently causes extrapulmonary disease, and has low sputum smear positivity in pulmonary $\mathrm{TB}$, which could result in delayed diagnosis of TB [34]. In our study, SPR of HIV among males aged 20-59 was very high as 39.64 , while SPR of HIV among male aged $\leq 19$ or $\geq 60$ and among female was 7.33 and 7.87. SPR of HIV among cases with extrapulmonary TB was 43.21, however, SPR of HIV among cases with pulmonary TB and among smearpositive TB was also 16.09 and 15.40 respectively, although those SPRs were smaller than that among extrapulmonary TB cases. Based on our results, we recommend that physicians should consider performing 
HIV tests among patients with TB, especially males aged 20-59 and those with extrapulmonary TB in South Korea. However, we could not completely disagree to the recommendation that all TB patients should undergo HIV testing (universal approach) $[1,17]$ because the SPRs of HIV among other groups such as pulmonary TB cases were not low. In our study, if only male TB patients between age 20 and 59 had undergone HIV testing, 17 cases (12.4\% of comorbid cases) with $\mathrm{TB} /$ HIV could be missed. On the other hand, if HIV screening were restricted to male TB patients aged 20-59 or patients with extrapulmonary TB, 11 cases $(8.0 \%$ of comorbid cases) could be missed. The guideline of South Korea recommends all TB patients should undergo HIV testing now.

It could also be thought that the high SPR of HIV among patients with $\mathrm{TB}$ suggests that $\mathrm{TB}$ increases the risk of contracting HIV, which was, to our knowledge, the first clinical suggestion. Some researchers reported that patients with TB have increased expression of coreceptors for HIV, increased levels of proinflammatory cytokines, and down-regulated RANTES(Regulated upon Activation, Normal T-cell Expressed, and Secreted), which increase susceptibility to HIV infection [9]. TB could also be a sentinel diagnosis which prompted investigation for HIV in these patients. However, this suggestion cannot be concluded in our study, considering that we could not ascertain whether HIV could have preceded TB or could have been detected simultaneously with TB in some patients.

There were some limitations in our study. First, as KTBS includes only TB patients who were notified [35], the data could not reflect all TB patients in South Korea. In addition, although HIV/AIDS national registry includes all confirmed HIV/AIDS cases, there can be many undiagnosed HIV/AIDS cases. However, given that the survey conducted in PHC showed $0.08 \%$ of TB patients were diagnosed as comorbidity with HIV by HIV screening test, which is similar to the result of database data $(0.07 \%$ among TB cases registered in KTBS had also be registered in HIV/AIDS registry), it was considered that our study sample could represent real life situation although there is no evidence that private and public units similarly follow the national recommendations. Second, although our survey supported the prevalence rate of TB/HIV cases from the population database data, it was not possible to compare cases within subgroups because the number of comorbid cases in the survey was too small: There were only six cases.

\section{Conclusions}

The burden of HIV and TB/HIV is still low in South Korea, which is a low prevalent area with HIV/AIDS and a country with intermediate TB burden. However, the increase in the number of HIV patients could be a potential threat to TB control in South Korea. In addition, it is recommended that physicians should consider performing HIV tests among TB patients, especially in higher-risk groups, such as young males with extrapulmonary TB in South Korea.

\section{Acknowledgements}

We appreciate the thoughtful advice of Jae-Joon Yim M.D., Young-Ae Kang M.D., Jeong Ym Bai and ByungHa Park, and extend our thanks to HyunJeong Lee at Florida University for assisting in the English translation of our manuscript.

\section{Author details}

'Division of HIV and TB Control, Korea Centers for Disease Control and Prevention, 194 Tongillo, Eunpyung-gu, Seoul, 122-701, Republic of Korea. ${ }^{2}$ Division of pulmonary and critical care medicine, Department of Internal Medicine, Seoul Metropolitan Government Seoul National University Boramae Medical Center, 39 Boramae Road, Dongjak-gu, Seoul, 156-707, Republic of Korea. ${ }^{3}$ Preventive Medicine, Gachon University of Medicine and Science, 534-2 Yeonsu3-dong, Yeonsu-gu, Incheon, 406-799, Republic of Korea. ${ }^{4}$ Division of AIDS, Korea Centers for Disease Control and Prevention, 194 Tongillo, Eunpyung-gu, Seoul, 122-701, Republic of Korea. ${ }^{5}$ Division of Rheumatology, Department of Internal Medicine, Seoul National University College of Medicine, 28 Yongon-dong, Jongno-gu, Seoul, 110-744, Republic of Korea. ${ }^{6}$ Korean Institute of Tuberculosis, Republic of Korea, 14 Woomyeondong, Seocho-gu, Seoul, 137-900, Republic of Korea.

\section{Authors' contributions}

$\mathrm{CHL}$ and JGN designed the study and wrote the article. JYH and JWA analyzed the data on HIV/AIDS. JHK helped in the design of the study. EJO and HSD conducted the questionnaire survey. HJK analyzed the data on TB. MKK and SSK performed the testing on HIV. HHK and DKO supervised the study. All authors read and approved the final manuscript.

\section{Competing interests}

The authors declare that they have no competing interests.

Received: 11 July 2009 Accepted: 12 March 2010

Published: 12 March 2010

\section{References}

1. World Health Organization: Global Tuberculosis Control: Surveillance, Planing, Financing: WHO report 2006 Geneva, Switzerland: World Health Organization 2008.

2. The Joint United Nations Programme on HIV/AIDS: AIDS epdemic update 2007 Geneva, Switzerland: Joint United Nations Programme on HIV/AIDS (UNAIDS) and World Health Organization (WHO) 2007.

3. Di Perri G, Cruciani M, Danzi MC, Luzzati R, De Checchi G, Malena M, Pizzighella S, Mazzi R, Solbiati M, Concia E, et al: Nosocomial epidemic of active tuberculosis among HIV-infected patients. Lancet 1989, 2(86788679):1502-1504

4. Raviglione MC, Harries AD, Msiska R, Wilkinson D, Nunn P: Tuberculosis and HIV: current status in Africa. AIDS 1997, 11(Suppl B):S115-123.

5. Fitzgerald DW, Desvarieux M, Severe $P$, Joseph $P$, Johnson WD Jr, Pape JW: Effect of post-treatment isoniazid on prevention of recurrent tuberculosis in HIV-1-infected individuals: a randomised trial. Lancet 2000, 356(9240):1470-1474.

6. Dye C, Espinal MA, Watt CJ, Mbiaga C, Williams BG: Worldwide incidence of multidrug-resistant tuberculosis. J Infect Dis 2002, 185(8):1197-1202.

7. Gandhi NR, Moll A, Sturm AW, Pawinski R, Govender T, Lalloo U, Zeller K, Andrews J, Friedland G: Extensively drug-resistant tuberculosis as a cause of death in patients co-infected with tuberculosis and HIV in a rural area of South Africa. Lancet 2006, 368(9547):1575-1580.

8. Madariaga MG, Lalloo UG, Swindells S: Extensively drug-resistant tuberculosis. Am J Med 2008, 121(10):835-844. 
9. Rosas-Taraco AG, Arce-Mendoza AY, Caballero-Olin G, Salinas-Carmona MC Mycobacterium tuberculosis upregulates coreceptors CCR5 and CXCR4 while HIV modulates CD14 favoring concurrent infection. AIDS Res Hum Retroviruses 2006, 22(1):45-51.

10. Nakata K, Rom WN, Honda Y, Condos R, Kanegasaki S, Cao Y, Weiden M: Mycobacterium tuberculosis enhances human immunodeficiency virus-1 replication in the lung. Am J Respir Crit Care Med 1997, 155(3):996-1003.

11. Greenberg AE, Lucas S, Tossou O, Coulibaly IM, Coulibaly D, Kassim S, Ackah A, De Cock KM: Autopsy-proven causes of death in HIV-infected patients treated for tuberculosis in Abidjan, Cote d'Ivoire. AIDS 1995, 9(11):1251-1254.

12. Cantwell MF, Binkin NJ: Tuberculosis in sub-Saharan Africa: a regional assessment of the impact of the human immunodeficiency virus and National Tuberculosis Control Program quality. Tuber Lung Dis 1996, 77(3):220-225.

13. Quigley MA, Mwinga A, Hosp M, Lisse I, Fuchs D, Porter JDH, GodfreyFaussett $P$ : Long-term effect of preventive therapy for tuberculosis in a cohort of HIV-infected Zambian adults. AIDS 2001, 15(2):215-222.

14. Girardi E, Antonucci G, Vanacore P, Libanore M, Errante I, Matteelli A, Ippolito G: Impact of combination antiretroviral therapy on the risk of tuberculosis among persons with HIV infection. AIDS 2000, 14(13):1985-1991.

15. Jones $\mathrm{L}$, Hanson DL, Dworkin MS, DeCock KM: HIV-associated tuberculosis in the era of highly active antiretroviral therapy. The Adult/Adolescent Spectrum of HIV Disease Group. Int J Tuberc Lung Dis 2000, 4(11):1026-1031.

16. World Health Organization: Strategic Framework to Decrease Burden of TB/ HIV Geneva, Switzerland: World Health Organization 2002.

17. World Health Organization: Interim Policy on Collaborative TB/HIV activities. Geneva, Switzerland: World Health Organization 2004.

18. Grimes DA, Schulz KF: Uses and abuses of screening tests. Lancet 2002, 359(9309):881-884.

19. Harris T, Panaro L, Phypers M, Choudhri Y, Archibald CP: HIV Testing among Canadian Tuberculosis Cases from 1997 to 1998. Can J Infect Dis Med Microbiol 2006, 17(3):165-168.

20. Korea Center for Disease Control and Prevention: Statistics on HIV/AIDS in Korea. [http://www.cdc.go.kr/kcdchome/jsp/home/common/brd/ COMMBRD0200Detail.jsp?boardid=1002\&boardseq $=21934 \&$ menuid $=100039 \&$ appid $=$ kcdchome\&contentid $=$ null\&pageNum $=2 \&$ tabin $x=1$ \&pageNo=\&q_value $=\% E C \% 97 \% 90 \% E C \% 9 D \% B 4 \% E C \% A 6 \%$ 88\&q_name=\&sub=1\&q_value=\%EC\%97\%90\%EC\%9D\%B4\%EC\%A6\%88], (Latest available date: 1 Jan 2010).

21. The Joint United Nations Programme on HIV/AIDS: 2006 Report on the Global AIDS Epidemic. Geneva, Switzerland: World Health Organization 2006.

22. Hong YP, Kim SJ, Lew WJ, Lee EK, Han YC: The seventh nationwide tuberculosis prevalence survey in Korea, 1995. Int J Tuberc Lung Dis 1998, 2(1):27-36.

23. Korean Statistical Information Service: Population estimate in South Korea. [http://www.kosis.kr], (Latest availabe data: 1 Jan 2010).

24. Lindholm J, Juul S, Jorgensen JO, Astrup J, Bjerre P, Feldt-Rasmussen U, Hagen C, Jorgensen J, Kosteljanetz M, Kristensen L, et al: Incidence and late prognosis of cushing's syndrome: a population-based study. J Clin Endocrinol Metab 2001, 86:117-123.

25. Ohsawa M, Kato K, Itai K, Tanno K, Fujishima Y, Konda R, Okayama A, Abe K, Suzuki K, Nakamura M, et al: Standardized Prevalence Ratios for Chronic Hepatitis C Virus Infection Among Adult Japanese Hemodialysis Patients. J Epidemiol 2009, 20(1):30-39.

26. Korea Center for Disease Control and Prevention: Statistics on Tuberculosis in South Korea. [http://tbfree.cdc.go.kr/tb/tb07.asp], (Latest available data: 1 Jan 2010).

27. Corbett EL, Watt CJ, Walker N, Maher D, Williams BG, Raviglione MC, Dye C: The growing burden of tuberculosis: global trends and interactions with the HIV epidemic. Arch Intern Med 2003, 163(9):1009-1021.

28. Faggiano F, Vigna-Taglianti FD, Versino E, Salamina G, Bugiani M: Tuberculosis incidence in Turin, Italy, 1973-1999. Int J Tuberc Lung Dis 2004, 8(2):171-179.

29. Martin V, Cayla JA, Bolea A, Castilla J: Mycobacterium tuberculosis and human immunodeficiency virus co-infection in intravenous drug users on admission to prison. Int J Tuberc Lung Dis 2000, 4(1):41-46.
30. Pablos-Mendez A, Blustein J, Knirsch CA: The role of diabetes mellitus in the higher prevalence of tuberculosis among Hispanics. Am J Public Health 1997, 87(4):574-579.

31. Moss AR, Hahn JA, Tulsky JP, Daley CL, Small PM, Hopewell PC: Tuberculosis in the homeless. A prospective study. Am J Respir Crit Care Med 2000, 162(2 Pt 1):460-464.

32. Smith DK, Gwinn M, Selik RM, Miller KS, Dean-Gaitor H, Ma'at PI, De Cock KM, Gayle HD: HIV/AIDS among African Americans: progress or progression? AIDS 2000, 14(9):1237-1248.

33. Centers for Disease Control and Prevention: Reported Tuberculosis in the United States, 1999. Atlanta: US Dept of Health and Human Services 2000.

34. Sharma SK, Mohan A, Kadhiravan T: HIV-TB co-infection: epidemiology, diagnosis \& management. Indian J Med Res 2005, 121(4):550-567.

35. Lew WJ, Lee EG, Bai JY, Kim HJ, Bai GH, Ahn DI, Lee JK, Kim SJ: An Internetbased surveillance system for tuberculosis in Korea. Int J Tuberc Lung Dis 2006, 10(11):1241-1247.

Pre-publication history

The pre-publication history for this paper can be accessed here: http://www. biomedcentral.com/1471-2334/10/66/prepub

doi:10.1186/1471-2334-10-66

Cite this article as: Lee et al:: The burden and characteristics of tuberculosis/human immunodeficiency virus (TB/HIV) in South Korea: a study from a population database and a survey. BMC Infectious Diseases 2010 10:66.

\section{Submit your next manuscript to BioMed Central and take full advantage of:}

- Convenient online submission

- Thorough peer review

- No space constraints or color figure charges

- Immediate publication on acceptance

- Inclusion in PubMed, CAS, Scopus and Google Scholar

- Research which is freely available for redistribution

Submit your manuscript at www.biomedcentral.com/submit
C) Biomed Central 